\title{
LINGUISTICS OF MODERN GEORGIAN MEDIA
}

Tinatin Zakarashvili,

Doctor of Social Sciences,

Professor of Journalism,

Georgian National University SEU

\begin{abstract}
Modern mass media, as an important means of informing the public, determines people's consciousness, shapes their interests and determines the mood. It has also successfully incorporated the role of an educator from the very beginning. Thus, the media linguistics plays a special role in spreading the native Georgian language, as well as in raising the literacy rate of the population. Language is the main tool to guide human cognitive activity.

Although, there are many examples of media trying to comply with linguistic norms, modern broadcasting fails to maintain proper Georgian; digital media being particularly full of many linguistic and stylistic errors. It should also be noted that electronic media is the only source of information for many, especially the young people. Given the high social importance, journalists should be careful with dealing with the language.

The development and transformation process of mass media in the global information space is not only indirectly but also directly reflected, especially in the formation of the Internet media linguistics. The current social and political changes in the country have also affected the process of language deformation.

The scientific article deals with the influence of media language on the linguistic features of the Georgian society. It discusses the problematic issues of modern publicist thinking, focusing on the linguistic distortions that modern journalists are characterized with.

The speech problem of media representatives is topical, complex and large-scale. Their speeches are the basis of the communicative interaction of the society, contribute to the linguistic influence, national identity, mutual understanding of people, perception of the world.

The media significantly influences the value system, mentality and literary norms used in any society. Violation of literary norms, which is observed in modern Georgian media, has a negative impact on the audience and the level of literary competence of the speakers.
\end{abstract}

Keywords: mass media, mass media linguistics, media texts, literary norms, TV discourse.

\section{Introduction}

In addition to informing the public, the media is responsible for providing upbringing and education. Journalism has been entrusted with an educational mission since the day it was born. It plays a major role in shaping and guiding public opinion, people's consciousness and their views.

People's lives have been significantly changed with the age of electronic information and modern mass media. The media is increasingly encroaching all aspect of human life and even direct its path. The media determines 
people's behavior, views and shapes their taste. Thus, journalists take a special responsibility in conveying each message, as the audience seems to absorb the words, sentences, phrases, and even the intonation.

Studies of Georgian linguistics, issues of spelling and Georgian literary norms are constantly underway. Many Georgian linguists and philologists have explored the above-mentioned issues and have accumulated interesting materials. But, albeit relatively little number of scholars ever argue about the spoken language of the media and linguistic errors. However, we do not know much about the specifics of the knowledge and experience journalists have accumulated in the field of modern Georgian media language and speech. This article is an attempt of such research and the solutions found to the mentioned issues serve as scientific novelty.

The subject of the research covers modern broadcasting and Internet media language and literary norms. The aim of the paper is to analyze the aspects of the language journalists and media representatives use, to determine the extent to which the media language exercises its influence on the linguistics of the audience and to review the linguistic situation in journalism. In order to achieve this goal, the information covered by the mass media will be analyzed by the method of content analysis and randomness; the nature of the errors will be identified and determined based on the solution of specific tasks:

- Based on the concept of speech culture developed by researchers, the main criteria for the speech of modern journalists and media people are determined;

- The impact of current processes in the Georgian language on the extent of journalists' literary skills will be discussed;

- Cases and main reasons for deviation from the norms of the Georgian literary language in the media will be studied;

- Recommendations will be offered to improve the journalist's speaking skills.

The structure of the paper is also conditioned by these tasks.

\section{The Influence of Media on Linguistics}

The language of the media plays an important role in spreading the Georgian linguistics, as well as raising the literacy rate of the population. On the one hand, mass communication complements the language; we are introduced to the current events through media channels. However, on the other hand, its influence changes linguistic norms, reducing the quality of linguistics. Though media was considered to serve as the gauge of the literary standards, nowadays it only distorts the language.

Language plays a dramatic role in determining the affiliation of a particular social or regional-ethnic community. A sense of the value of the mother tongue is a fundamental component of understanding the place that a person occupies in society. A language can be a valuable resource for an individual or group that needs to be maintained and reflected in their handling of that language. ${ }^{1}$

Mistakes are not uncommon in printed publications and online media; proper Georgian is rarely heard from the TV screen. Given the attitudes of young people, television, especially the Internet, is the only source and "light" in the world of information. Thus, the media should be careful with handing the Georgian language.

${ }^{1}$ K. Gabunia, "Linguistic Situation in Modern Georgia”, International Journal of Multilingual Education, 2014, \# 3, p. 46. 
It is important for journalists not only to adequately cover current events and processes, but also to pay attention to the forms of expression, reflection and how well they write and speak on TV and radio or online media, since today they happen to be the ones who define the culture of modern audiences.

The problem of journalists' speech is topical for a number of reasons. It is their speeches that contribute to the linguistic impact, as the main means of communication is the native language. Communication with the media affects each person in all directions, not just the content of media programmes. This aspect naturally puts on the agenda the need to consider the impact of the language and style of media representatives on public awareness.

The development of modern Georgian media, the growth rate and character of media channels are conditioned by the current democratic, political, economic and social processes in the country. All these trends influence the language of all mass media, especially electronic media, as new challenges directly affect the purity of spoken language.

\section{The Language of Modern Media}

The linguistic change of the media is also conditioned by objective reasons: our language is a reflection of our own life. Also, in the 21 st century, there is a danger of contamination of the language with foreign words and slang, and it is necessary to find a golden interval that will enrich the modern language with neologisms or foreign words and preserve the richness and diversity of the Georgian language.

The most important professional competence for Georgian journalists lies in the command of the Georgian language, involving the ability to express their opinions correctly, clearly, correctly, to adhere to the standards of speech, utilizing its resources.

For a person, language is not only a means of civic and professional communication, but also an information space, a cultural environment that creates and enhances national identity. That is why any media person, including journalist, or reporter must meet certain requirements, with proper speech and observance of linguistic norms, they must be exemplary for the audience.

Research has shown that journalists grossly violate the literary norms. On the one hand, this is a result of the editorial and speech policies of TV channels: presenters and reporters are required to read/speak quickly. On the other hand, establishing a general tendency to convey information in the form of speech leads to distortion of diction, words, sentences.

In the Georgian media space, we often find linguistically and stylistically incorrect texts as well as foreign words, which are difficult for most of the society to understand. The media language of the last decade is characterized by an abundance of words borrowed from foreign languages, mostly English, or rather American English. However, it is said that the language itself discards the necessary and retains only the necessary.

There have been many periods in the history of the Georgian language of adding foreign words. In everyday life various events and news take place and as a result, new words, terms enter the vocabulary. Today, everyone is familiar with the following words: "marketing", "dealer", "broker", "computer". With technical progress a number of words are spread around the world and settled in different languages, especially if no proper equivalent is not available in the host language.

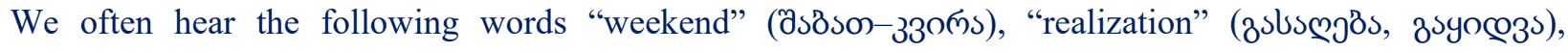

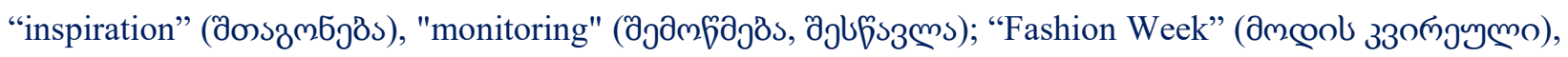




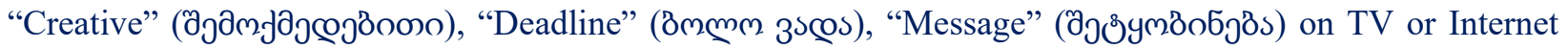
media whose equivalents available in Georgian.

In addition to barbarisms, ${ }^{2}$ Georgian media also speaks grammatically incorrect language. The audience, often even unintentionally, imitates him. The viewer's ear is so accustomed to the linguistic mistakes made by journalists that sometimes even a number of mistakes go unnoticed.

In Georgian broadcast and network media we often find words ended in the "for" postpositions. For example, love for the homeland, respect for the elderly, faith in the future. Of course, these words are used without postpositions in genitive case. ${ }^{345}$

A number of linguistic-stylistic errors have been revealed due to the research, made by Georgian journalists. The author of the article also presents the most common mistakes in the format of "right/ wrong" and we did not find their translation appropriate due to linguistic peculiarities.

As for the phonetic changes, journalists are speaking at an increasingly fast pace from TV or radio, there are often cases of sound reduction, i.e. weakening of the sound and syllable, or its complete "loss". The intonation of Georgian natural speech and natural linguistic models are distorted. ${ }^{67}$ Mistakes are made by journalists by ignoring the norms of intonation in narrative sentences, by incorrectly splitting phrases, distorting meanings, the lack of pauses between phrases.

It should also be noted that reporters constantly have to work under pressure and are overwhelmed by the abundance of information; however, they must definitely look for ways to correct errors in their speech.

It will not be easy to establish an ideal media speech, but specialists, teachers and, most importantly, journalists must unanimously realize that in order to maintain the dignity of this profession in the future, it is necessary to design and implement appropriate measures to address this problem. In order to improve the language of modern media, it is possible to involve consultant specialists in the process of training journalists more intensively and to train them in language skills. No less important is the promotion of linguistic knowledge in print and electronic media.

\section{Conclusion}

The media creates a special audiovisual effect influencing any individual. Thus, the issue of media responsibility before the public gets seriously raised.

\footnotetext{
${ }^{2}$ Dictionary of Barbarisms, available here: https://barbarisms.ge/whatis/ [L. s. 26.03.2021].

${ }^{3}$ Georgian Week, 2020, January 14, is available at: Internetresource

http://kartuli.kvira.ge/2020/01/14/\%E1\%83\%9B\%E1\%83\%94\%E1\%83\%A0\%E1\%83\%94-

$\%$ E1\%83\%A0\%E1\%83\%90-\%E1\%83\%97\%E1\%83\%A3-

$\%$ E1\%83\%97\%E1\%83\%A5\%E1\%83\%95\%E1\%83\%94\%E1\%83\%9C\%E1\%83\%98-\%E1\%83\%AA $\%$ E1\%83\%90-

$\% \mathrm{E} 1 \% 83 \% \mathrm{~A} 9 \% \mathrm{E} 1 \% 83 \% 95 \% \mathrm{E} 1 \% 83 \% 94 \% \mathrm{E} 1 \% 83 \% 9$ C/ [L. s. 26.03.2021].

${ }^{4}$ PS News.ge, December 17, 2013, available here: http://psnews.ge/index.php?m=68\&news_id=55176 [L. s. 26.03.2021]

${ }^{5}$ New Post, September 7, 2016, available here: https://www.newposts.ge/?newsid=118329 [L. s. 26.03.2021].

6 "Sports Hour", 2020, October 7, available here: https://www.facebook.com/sportrustavi2/videos/257600352504916 [L. s. 26.03.2021].

7"Rustavi 2", Good Morning Georgia, 2021, February 26, is available here:

https://www.facebook.com/rustavi2/videos/793072984617175/ [ L. s. 26.03.2021].
} 
Unfortunately, the linguistic mistakes made by journalists do not seem to be noticed, even the ear seems to get accustomed to them. It is therefore important to focus on this problem, since incorrect word formations and mispronunciations settle into daily speech.

The research has shown that linguistically and stylistically flawed texts are often found in the Georgian media space. The so-called "borrowed words" are widely used in the speech of TV journalists. Apart from barbarisms, one can often hear/read words ending in "for" postposition on Georgian broadcasting and online media.

As for the phonetic changes, we can see the cases of weakening the sound and the syllable, or its complete "loss" in the speech of the journalists delivered on TV and radio at an increasingly fast pace.

The intonation of Georgian natural speech changes as does the natural linguistic models. Due to the lack of intonation norms, incorrect division of phrases, lack of pauses between phrases, journalists make mistakes in narrative sentences.

In order to improve the linguistic level, it is possible to involve consultant specialists in the process of training journalists more intensively into command of language. It is also necessary to popularize linguistic knowledge in electronic and printed media.

Solving problems requires a systemic approach. It is also important for the state to pursue a targeted policy for the protection and development of the language.

In conclusion, the aim of the research was not to investigate and evaluate all kinds of linguistic errors or shortcomings in the media from the position of a linguist. We tried to show the general picture seen through the eyes of a journalist, which presented the linguistic situation and tendencies in the Georgian media and defined recommendations for correcting the problem. 


\section{Bibliography:}

1. Kakha Gabunia, "The Linguistic Situation in Modern Georgia”, International Journal of Multilingual Education, \# 3, p. 46, 2014;

http://www.multilingualeducation.org/storage/uploads/articles_contents/141215024122.pdf [Last seen 26.03.2021];

2. Dictionary of Barbarisms. https://barbarisms.ge/whatis/ [Last seen 26.03.2021];

3. “Georgian Week", 2020, January 14, Internetresource [Last seen 26.03.2021];

4. PS News.ge, December 17, 2013. http://psnews.ge/index.php?m=68\&news_id=55176 [Last seen 26.03.2021];

5. New Post, September 07, 2016. https://www.newposts.ge/?newsid=118329 [Last seen 26.03.2021];

6. “Netgazeti”, 2021, February 24, https://netgazeti.ge/news/522028/ [Last seen 26.03.2021];

7. "Sports Hour", 2020, October 7. https://www.facebook.com/sportrustavi2/videos/257600352504916 [Last seen 26.03.2021];

8. Rustavi 2, "Good Morning Georgia", 2021, February 26. https://www.facebook.com/rustavi2/videos/793072984617175/ [Last seen 26.03.2021];

9. Avtandil Arabuli, "Culture of Georgian Speech”, Tbilisi, 2008;

10. Shukia Afridonidze, "Our Georgian Language”, Tbilisi, 2002;

11. Ketevan Giorgobiani, Manana Datukishvili, "Issues of Georgian Linguistics”, Tbilisi, 2008;

12. Tsotne Kikvidze, "Issues of Spelling and Orthography of the Modern Georgian Literary Language", Technical University, Tbilisi, 2000;

13. Rusudan Saghinadze, "Norms of Modern Georgian Literary Language - Problems and Ways to Solve Them", http://dl.sangu.edu.ge/pdf/qapvols/qap_v2_14.pdf [Last seen 26.03.2021];

14. Akaki Shanidze, "Actual Issues of Literary Georgian," Ganatleba Publishing House, Tbilisi, 1979. 